\section{Infection after cyanoacrylate injection: a fatal complication in a patient with portal hypertension associated with common variable immuno- deficiency}

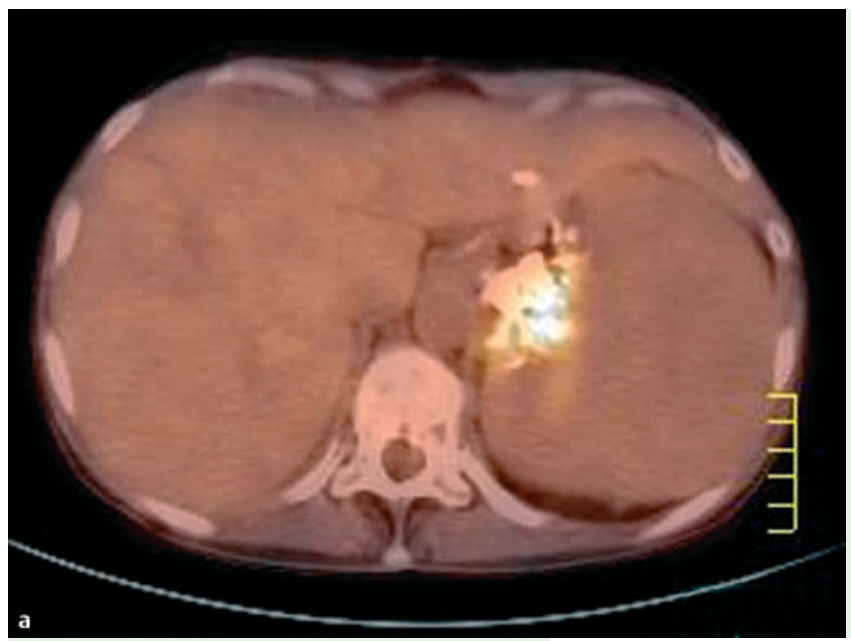

Figure 1 Positron emission tomographic scan performed in May 2006 after ${ }^{18} \mathrm{~F}$-fluorodeoxyglucose $\left({ }^{18} \mathrm{~F}-\mathrm{FDG}\right)$ injection $(5 \mathrm{MBq} / \mathrm{kg})$ : fused transaxial view (a) and coronal view (b). Note the ${ }^{18} \mathrm{~F}$-FDG uptake at the location of the cyanoacrylate sclerotherapy of the gastric varices.

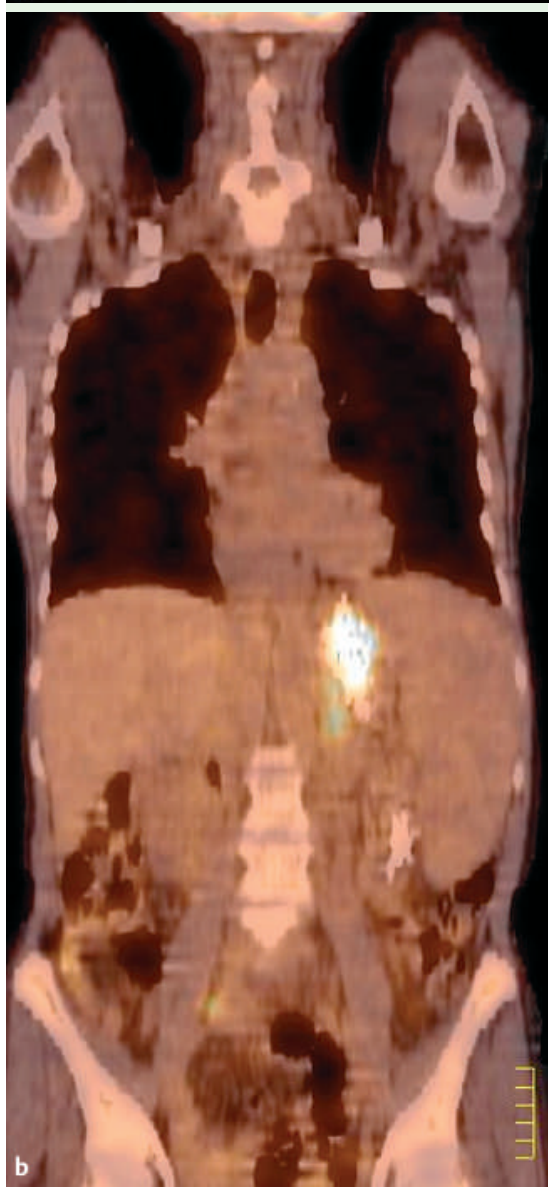

A 54-year-old woman was referred in 2002 because of recurrent pneumonitis associated with bronchiectasis. Common variable immunodeficiency was diagnosed (the serum gammaglobulin level

was $0.09 \mathrm{~g} / \mathrm{dL}$ [normal range $1.2-1.5 \mathrm{~g}$ / $\mathrm{dL}]$ ), and she was treated with immunoglobulins. In 2004, gastroscopy revealed stage 2 esophageal and gastric varices, caused by nodular regenerative hyperplasia-related portal hypertension. In 2005 the patient developed Pseudomonas aeruginosa pneumonitis. In February 2006, endoscopic injection sclerotherapy with cyanoacrylate glue injections was performed for gastric variceal bleeding, with antibiotic prophylaxis with cefazoline. In April 2006 she had another hematemesis and further endoscopic injection sclerotherapy was required.

In May 2006, it was believed that she had developed an infection associated with the cyanoacrylate glue on the basis of the following features: (a) she had a fever and this began after the cyanoacrylate injection; (b) bronchial bacteriology was negative; (c) there was persistent sepsis, with blood samples positive for P. aeruginosa despite prolonged and specific antibiotic therapy; and (d) the findings of positron emission tomography using ${ }^{18} \mathrm{~F}$ fluorodeoxyglucose ( $\left.{ }^{18} \mathrm{~F}-\mathrm{FDG}\right)$ radiotracer, with uptake at the location of the sclerotherapy (see $\bullet$ Figure 1). Eventually, the patient was treated with meropenem and colimycin. Gastrectomy, porto-caval anastomosis, and thrombectomy of the splenic vein were performed. Multiresistant $P$. aeruginosa was isolated from all samples, including the cyanoacrylate thrombus. The patient died from intractable septic shock.

Fatal complications of endoscopic injection sclerotherapy, such as glue embolism, are rare [1]. Septicemia after endoscopic injection sclerotherapy has been reported in only a few patients who had received the recommended prophylactic antibiotics [2]. The majority of hypogammaglobulinemic patients suffer from bronchiectasis as a result of recurrent pulmonary sepsis [3]. The "usual" enterobacterial antibiotic prophylaxis (e.g. with cefazolin) might not be suitable in patients with bronchiectasis, especially in the setting of common variable immunodeficiency [4]. Of note in our patient, we were able to pinpoint the site of the infection in the glue using ${ }^{18} \mathrm{~F}-\mathrm{FDG}$ positron emission tomographic imaging [5].

In conclusion, sclerotherapy with cyanoacrylate in patients with portal hypertension related to common variable immunodeficiency entails a specific risk of fatal sepsis, despite antibiotic prophylaxis and immunoglobulin treatment.

\section{Acknowledgments \\ $\nabla$}

We are grateful to Professor Michel Wolff, Eric Oksenhendler, and Dr. Sophie Hillaire for their helpful discussion.

Endoscopy_UCTN_Code_CPL_1AH_2AC

O. Lidove ${ }^{1}$, A. Gervais ${ }^{2}$, M. Malphettes ${ }^{3}$, A. Sauvanet ${ }^{4}$, J.-L. Moretti ${ }^{5}$, T. Papo ${ }^{1}$ Faculté de Médecine René Diderot, Department of Internal Medicine, Bichat Hospital, Paris, France

2 Department of Infectious Diseases, Bichat Hospital, Paris, France

3 Department of Immunology and Haematology, Saint-Louis Hospital, Paris, France

4 Department of Digestive Surgery, Beaujon Hospital, Clichy, France Department of Nuclear Medicine, Saint-Louis Hospital, Paris, France 


\section{References}

1 De Franchis R. Evolving consensus in portal hypertension: report of the Baveno IV consensus workshop on methodology of diagnosis and therapy in portal hypertension. J Hepatol 2005; 43: 167-176

2 Yarze JC. Septic complications after variceal cyanoacrylate injection. Gastrointest Endosc 2005; 61: 186

3 Thickett KM, Kumararatne DS, Banerjee AK et al. Common variable immune deficiency: respiratory manifestations, pulmonary function and high-resolution CT scan findings. QJM 2002; 95: 655-662
4 Angrill J, Agusti C, de Celis $R$ et al. Bacterial colonisation in patients with bronchiectasis: microbiological pattern and risk factors. Thorax 2002; 57: 15 - 19

5 Bleeker-Rovers CP, Vos FJ, Wanten GJ et al. 18F-FDG PET in detecting metastatic infectious disease. J Nucl Med 2005; 46: 2014 2019

Bibliography

DOI 10.1055/s-2007-966546

Endoscopy 2007; 39: E180 -E181

(c) Georg Thieme Verlag KG Stuttgart · New York . ISSN 0013-726X
Corresponding author

o. Lidove, MD

Hôpital Bichat Claude-Bernard

46 Rue Henri Huchard

75722 Paris

Cedex 18

France

Fax: +33-1-40-25-88-45

olivier.lidove@bch.aphp.fr 